\title{
Identifying existing Choosing Wisely recommendations of high relevance and importance to hematology
}

Lisa K. Hicks, ${ }^{1 \star}$ Anita Rajasekhar, ${ }^{2}$ Harriet Bering, ${ }^{3 \dagger}$ Kenneth R. Carson, ${ }^{4 \dagger}$ Judith Kleinerman, ${ }^{5 \dagger}$ Vishal Kukreti, ${ }^{6 \dagger}$ Alice Ma, ${ }^{7 \dagger}$ Brigitta U. Mueller, ${ }^{8 \dagger}$ Sarah H. O’Brien, ${ }^{9 \dagger}$ Julie A. Panepinto, ${ }^{10 \dagger}$ Marcelo C. Pasquini, ${ }^{11 \dagger}$ Ravi Sarode, ${ }^{12 \dagger}$ and William A. Wood ${ }^{7 \dagger}$

Choosing Wisely (CW) is a medical stewardship initiative led by the American Board of Internal Medicine Foundation in collaboration with professional medical societies in the United States. In an effort to learn from and leverage the work of others, the American Society of Hematology CW Task Force developed a method to identify and prioritize CW recommendations from other medical societies of high relevance and importance to patients with blood disorders and their physicians. All $380 \mathrm{CW}$ recommendations were reviewed and assessed for relevance and importance. Relevance was assessed using the MORE ${ }^{\text {TM }}$ relevance scale. Importance was assessed with regard to six guiding principles: harm avoidance, evidence, aggregate cost, relevance, frequency and impact. Harm avoidance was considered the most important principle. Ten highly relevant and important recommendations were identified from a variety of professional societies. Recommendations focused on decreasing unnecessary imaging, blood work, treatments and transfusions, as well as on increasing collaboration across disciplines and considering value when recommending treatments. Many CW recommendations have relevance beyond the society of origin. The methods developed by the ASH CW Task Force could be easily adapted by other Societies to identify additional CW recommendations of relevance and importance to their fields.

Am. J. Hematol. 91:787-792, 2016. @ 2016 Wiley Periodicals, Inc.

\section{Introduction}

Choosing Wisely (CW) is a medical stewardship campaign initiated by the American Board of Internal Medicine (ABIM) Foundation. To date more than 60 different medical professional societies have participated in the campaign by creating and promoting lists of tests and treatments that physicians and patients should question. The campaign has had a broad impact in healthcare, both by increasing awareness of overutilization [1], and in some instances by triggering changes in practice [2].

Since the CW campaign began in 2012 the number of participating societies and subsequent recommendations have grown dramatically. There are more than $380 \mathrm{CW}$ recommendations listed on the ABIM website [3]. Many of the recommendations have relevance beyond the field from which they originated. Yet strategies to raise awareness of $\mathrm{CW}$ recommendations have tended to direct clinicians to recommendations made by their parent societies [4]. Increasing awareness of a wider breadth of recommendations may ultimately help clinicians curb overutilization in medicine.

The American Society of Hematology (ASH) has previously released two lists of Choosing Wisely recommendations [5,6]. In 2015, the ASH CW Task Force developed a methodology to systematically identify and prioritize CW recommendations from other professional societies of relevance and importance to the practice of hematology. A top ten list of non-ASH CW recommendations relevant and important to the care of patients with blood conditions was developed and is presented below.

\section{Methods}

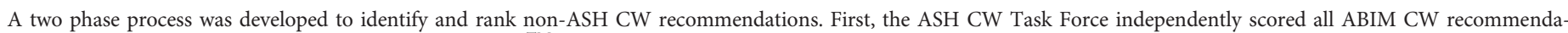

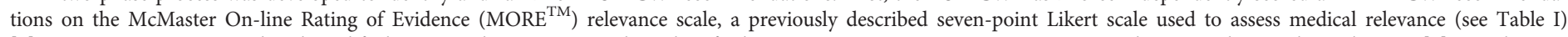

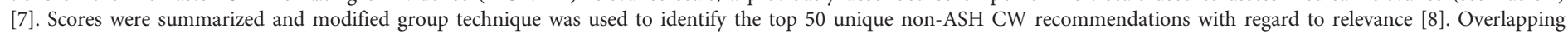

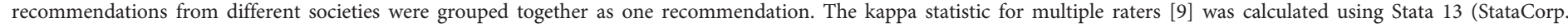

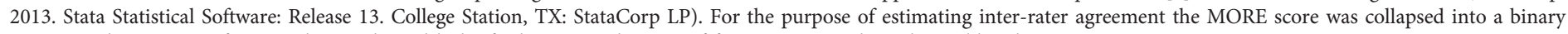
outcome where scores of one to three indicated lack of relevance and scores of four to seven indicated possible relevance.

\footnotetext{
${ }^{1}$ St. Michael's Hospital, University of Toronto, Toronto, Ontario, Canada; ${ }^{2}$ University of Florida, Gainesville, Florida; ${ }^{3}$ Harvard Vanguard Medical Associates, Beverly, Massachusetts; ${ }^{4}$ Washington University, St. Louis, Missouri; ${ }^{5}$ Medical Specialists of Taunton, Taunton, Massachusetts; ${ }^{6}$ University of Toronto, University Health Network, Toronto, Ontario; ${ }^{7}$ University of North Carolina, Chapel Hill, North Carolina; ${ }^{8}$ All Children's Hospital Johns Hopkins Medicine, St. Petersburg, Florida; ${ }^{9}$ Nationwide Children's Hospital, Columbus, Ohio; ${ }^{10}$ Medical College of Wisconsin/Children's Hospital of Wisconsin, Milwaukee, Wisconsin; ${ }^{11}$ Medical College of Wisconsin, Milwaukee, Wisconsin; ${ }^{12}$ UT Southwestern Medical Center, Dallas, Texas

${ }^{\dagger}$ Listed in alphabetical order due to equal contributions.

Disclosure: The authors declare no competing financial interests.

*Correspondence to: Lisa K. Hicks; 30 Bond St. Rm 2-084 Donnelly Wing, Toronto, ON M5B 1W8, Canada. E-mail: hicksl@smh.ca

Received for publication: 26 January 2016; Revised: 26 April 2016; Accepted: 3 May 2016

Am. J. Hematol. 91:787-792, 2016.

Published online: 6 May 2016 in Wiley Online Library (wileyonlinelibrary.com).

DOI: $10.1002 /$ ajh.24412
} 
TABLE I. The MORE ${ }^{\mathrm{TM}}$ Scale for Relevance

\begin{tabular}{|c|c|}
\hline Score & Description \\
\hline 7 & Directly and highly relevant \\
\hline 6 & Definitely relevant \\
\hline 5 & Probably relevant \\
\hline 4 & $\begin{array}{l}\text { Possibly relevant-Likely of indirect or peripheral } \\
\text { relevance at best }\end{array}$ \\
\hline 3 & Possibly not relevant \\
\hline 2 & Probably not relevant: content only remotely related \\
\hline 1 & Definitely not relevant: completely unrelated content area \\
\hline
\end{tabular}

In the second phase of the project, the ASH CW Task Force was asked to score each of the remaining $50 \mathrm{CW}$ recommendations between one and ten for prioritization for inclusion on a top ten list of non-ASH CW recommendations. Task force members were asked to consider the six guiding principles outlined in Table II (listed in order of importance). Avoiding harm to patients was considered the preeminent guiding principle. Modified group technique [8] was used to select the top ten CW recommendations from other specialty societies of relevance and importance to the care of patients with hematologic disease.

The ASH CW Task Force was comprised of 13 members: five men and eight women. All 13 members participated in both phases of item selection. Malignant, nonmalignant, lab-based, adult and pediatric hematologists were all represented on the Task Force.

\section{Results}

All ABIM CW recommendations posted on the ABIM CW website [5] were compiled at the end of April, 2015. At that time, there were 65 participating professional societies (excluding ASH) contributing 5-15 recommendations each, for a total of 380 individual recommendations. 261 (69\%) of the CW recommendations received an average relevance score of less than four suggesting limited relevance to the practice of hematology. The kappa statistic for interrater agreement was 0.43 , suggesting moderate inter-rater agreement on relevance [10]. The top ten CW recommendations from other professional societies relevant and important to the care of patients with blood diseases are outlined in Table III. The highlighted CW recommendations come for 13 different societies. Two of the recommendations were made by three or more different specialty societies.

\section{Discussion}

The first CW recommendation on our top ten list is an item that recommends against imaging for pulmonary embolism (PE) in the absence of moderate or high pretest probability. Slightly different versions of this recommendation were made by the American College of Radiology, the American College of Physicians, the American College of Chest Physicians and American Thoracic Society, and the American College of Emergency Physicians. The number of societies making this recommendation likely reflects both its importance and the large number of medical specialties involved in the diagnosis and management of PEs.

Recent data suggests that computed tomography scans with pulmonary angiography (CT-PA's) are being overemployed in all clinical settings to investigate for the possibility of a PE [11]. Poor patient selection, ready access to CT-PAs, patient expectations, and concern for malpractice litigation all likely contribute to overutilization of this imaging modality. Importantly however, despite a dramatic increase in the use of CT-PA's over the recent years, there is no evidence that clinically important patient outcomes have improved. Therefore, the risks and benefits of CT-PA's should be carefully considered and our current practice patterns for the evaluation of $\mathrm{PE}$ should be reexamined to align with evidence-based guidelines.
TABLE II. Guiding Principles for the ASH Choosing Wisely Campaign

\begin{tabular}{|c|c|}
\hline 1. Harm avoidance & $\begin{array}{l}\text { Recommendations should aim to reduce poten- } \\
\text { tial harm to patients }\end{array}$ \\
\hline 2. Evidence & Recommendations should be evidence-based \\
\hline 3. Cost & $\begin{array}{l}\text { Recommendations should aim to decrease the } \\
\text { cost of health care }\end{array}$ \\
\hline 4. Frequency & $\begin{array}{l}\text { Recommendations should target tests, proce- } \\
\text { dures or treatments that are common }\end{array}$ \\
\hline $\begin{array}{l}\text { 5. Purview of the } \\
\text { hematologist }\end{array}$ & $\begin{array}{l}\text { Recommendations should target tests, proce- } \\
\text { dures or treatments within the purview of the } \\
\text { hematologist }\end{array}$ \\
\hline 6. Impact & $\begin{array}{l}\text { Recommendations that are likely to have greater } \\
\text { impact (lead to greater positive changes) } \\
\text { should be prioritized over those of lesser } \\
\text { impact }\end{array}$ \\
\hline
\end{tabular}

CT-PA's deliver between 2.2 and $7 \mathrm{mSv}$ of radiation depending on body habitus and protocol [12]. This dose of radiation has been associated with a small, but significant increased life-time risk of cancer, particularly in young women where radiation-induced breast cancer is a concern [13-15]. Contrast-induced nephropathy is also a concern especially in patients who may subsequently be started on anticoagulation. Scans also frequently detect incidental findings triggering further testing with incumbent risks. The improved resolution of CTPA's has led to increased detection of small subsegmental PE's. Whether these PE's truly warrant aggressive anticoagulation to improve patient outcomes is debated [16].

Importantly, in the setting of low pretest probability imaging for $\mathrm{PE}$ is likely unnecessary. Diagnostic algorithms utilizing clinical features such as the Wells criteria, PERC tool and sensitive D-dimer testing can be used to safely rule out $\mathrm{PE}$ in many low risk patients without the need for imaging [17]. A large meta-analysis of 12 studies showed that the overall proportion of missed PE's using the PERC tool was only $0.3 \%$ [18]. More recently, a randomized controlled trial also suggested that utilizing pretest probability to avoid imaging in low risk patients is both safe and cost-saving [19]. Taken together, there is an urgent need for institutions to develop protocols incorporating clinical decision rules and laboratory data to optimally rule out $\mathrm{PE}$ while minimizing the number of patients exposed to CT-PA's.

The second CW item of high relevance and importance to hematology is a recommendation against routine inherited thrombophilia testing in patients undergoing an infertility evaluation. This recommendation comes from the American Society for Reproductive Medicine and is a commonly faced reason for hematology referral by both patients and their providers. Infertility is an extremely common disorder affecting $5-15 \%$ of women [20,21]. Given the potential frequency of infertility evaluation and the broad differential diagnosis of infertility, investigations should be judicious, evidence-based, and should minimize harm to the patient. Conflicting reports exist regarding a possible association between inherited thrombophilia and infertility $[22,23]$. On balance, the evidence does not support a strong association. More importantly, studies demonstrating that thrombophilia test results can be successfully used to guide management of infertility are lacking. Thrombophilia testing in any setting is fraught with false interpretation of tests leading to perpetuation of a thrombophilia diagnosis in the patient's medical records, high costs and minimal potential benefit. Further, inappropriate thrombophilia testing could potentially also lead to inappropriate use of anticoagulants, increased patient anxiety and difficulties obtaining insurance in these young and typically healthy individuals. Low-molecular weight heparin, even in prophylactic doses during pregnancy, can have several drawbacks including the inconvenience of daily self-injections, cost, bleeding, and decreased access to neuroaxial anesthesia if used in 
TABLE III. The Top Ten Non-ASH Choosing Wisely Recommendations of Relevance and Importance to Hematology

\begin{tabular}{|c|c|}
\hline Recommendation & Professional society \\
\hline $\begin{array}{l}\text { 1. Don't image for suspected pulmonary embolism (PE) without moderate or high pretest } \\
\text { probability. }\end{array}$ & $\begin{array}{l}\text { American College of Radiology } \\
\text { American College of Physicians } \\
\text { American College of Chest Physicians } \\
\text { and American Thoracic Society } \\
\text { American College of Emergency Physicians }\end{array}$ \\
\hline $\begin{array}{l}\text { 2. Don't routinely order thrombophilia testing on patients undergoing a routine infertility } \\
\text { evaluation. }\end{array}$ & American Society for Reproductive Medicine \\
\hline $\begin{array}{l}\text { 3. Don't perform repetitive } \mathrm{CBC} \text { and chemistry testing in the face of clinical and lab } \\
\text { stability. }{ }^{\text {. }}\end{array}$ & $\begin{array}{l}\text { Society of Hospital Medicine - } \\
\text { Adult Hospital Medicine } \\
\text { American Association of Blood Banks } \\
\text { Critical Care Societies Collaborative-Critical Care }\end{array}$ \\
\hline 4. Don't transfuse red blood cells for iron deficiency without hemodynamic instability. & American Association of Blood Banks \\
\hline $\begin{array}{l}\text { 5. Avoid using PET or PET-CT scanning as part of routine follow-up care to monitor for a } \\
\text { cancer recurrence in asymptomatic patients who have finished initial treatment to elimi- } \\
\text { nate the cancer unless there is high-level evidence that such imaging will change the } \\
\text { outcome }\end{array}$ & American Society of Clinical Oncology \\
\hline $\begin{array}{l}\text { 6. Don't delay palliative care for a patient with serious illness who has physical, psycholog- } \\
\text { ical, social or spiritual distress because they are pursuing disease-directed treatment }\end{array}$ & $\begin{array}{l}\text { American Academy of Hospice a } \\
\text { nd Palliative Medicine }\end{array}$ \\
\hline $\begin{array}{l}\text { 7. Don't place, or leave in place, peripherally inserted central catheters for patient or pro- } \\
\text { vider convenience }\end{array}$ & Society of General Internal Medicine \\
\hline $\begin{array}{l}\text { 8. Don't use white cell stimulating factors for primary prevention of febrile neutropenia for } \\
\text { patients with less than } 20 \text { percent risk for this complication }\end{array}$ & American Society of Clinical Oncology \\
\hline $\begin{array}{l}\text { 9. Don't use expensive medications when an equally effective and lower-cost medication } \\
\text { is available }\end{array}$ & American College of Preventive Medicine \\
\hline $\begin{array}{l}\text { 10. Don't routinely transfuse fresh frozen plasma and platelets prior to abdominal para- } \\
\text { centesis or endoscopic variceal band ligation }\end{array}$ & $\begin{array}{l}\text { American Association for the Study } \\
\text { of Liver Diseases }\end{array}$ \\
\hline
\end{tabular}

a Wording reflects that of the Radiology recommendation, other listed societies have similar recommendations, some explicitly recommended D-Dimer testing prior to imaging.

b Wording reflects that of the Society of Hospital Medicine, other listed Societies made similar recommendations.

proximity to delivery time. Therefore, widespread testing for congenital thrombophilia in the infertility setting could have substantial resource implications with little anticipated benefit.

The third CW recommendation of high importance and relevance to the care of patients with blood diseases is from the Society of Hospital Medicine and recommends against repetitive complete blood cell and chemistry testing in the face of clinical and lab stability. Similar recommendations were made by the American Association of Blood Banks (AABB) and the Critical Care Societies Collaborative-Critical Care. Human blood is a scarce resource. It has been estimated that every year four times as much blood is collected for testing, and ultimately disposed of, than is transfused worldwide (24). Laboratory testing is the single-highest practiced medical activity across all specialties and health care settings. Approximately $27 \%$ of all orders on admission are avoidable and $63 \%$ of orders are avoidable for the remainder of the hospitalization [25]. Only 1-5\% of laboratory tests result in some form of management action by the health care team [26]. Routine laboratory tests not only increase direct costs but also increase aggregate indirect expenses from subsequent downstream activities, such as prescriptions, imaging, surgeries, lengthened hospital stays, all of which place patients at risk for preventable medical errors. Furthermore, patients are subjected to these unnecessary laboratory tests that yield no information or, worse, misinformation. Interestingly, geographic differences in laboratory utilization exist without any obvious disparity in quality of care or clinically relevant outcomes [27]. In both the inpatient and outpatient setting a growing body of literature documents a low diagnostic yield from routine blood work [28,29]. Moreover, anemia caused by repeated blood draws is a well-recognized complication of hospital care [30,31]. In some patients without the bone marrow reserve or erythropoietin drive to compensate for iatrogenic blood loss, repeated lab tests can lead to otherwise preventable packed red cell transfusions which have inherent risks. In critical care units, prospective data suggest that strategies to reduce daily blood draws result in less anemia, substan- tial cost-saving, and have no negative impact on other clinical outcomes [29,31]. A simple and effective educational intervention of informing physicians of the charges for laboratory tests and their personal utilization patterns has been shown to reduce the number of laboratory tests ordered and laboratory expenditures [32]. It is recommended that blood testing be part of a reasoned diagnostic and management plan as opposed to automatic. Thus in some settings daily blood work may be appropriate for a short period of time; while in others no blood tests may be required. Developing test-ordering containment strategies through multidimensional approaches aimed at changing provider and system culture affords an opportunity to improve quality and reduce costs. Given their understanding of iatrogenic anemia, and their placement as leaders in the laboratory and transfusion environments, many hematologists are well positioned to develop initiatives addressing this type of overutilization.

The fourth $\mathrm{CW}$ recommendation selected by the ASH CW task force is a recommendation from the $\mathrm{AABB} C W$ campaign. The $\mathrm{AABB}$ advises against transfusing red blood cells for iron deficiency in the absence of hemodynamic instability. This is a particularly relevant recommendation for the hematologist as iron deficiency anemia due to a variety of causes is an extremely common reason for consultation with a hematologist. Iron deficiency is under-recognized, under-treated, or not properly followed in transitions of health care settings in 35-65\% of cases [33-35]. In addition, patients at risk for developing iron deficiency (e.g., bariatric surgery patients) are often inadequately monitored or educated on the signs and symptoms of iron deficiency leading to late stage presentations. Despite the availability of cheaper and safer therapies for iron deficiency anemia, packed red blood cell transfusions have become a reflexive approach. A proactive strategy of treating iron deficiency anemia before it becomes severe is vital. Many patients with moderate to severe chronic iron deficiency anemia have healthy hematopoietic systems and will undergo brisk erythropoiesis when iron deficiency is corrected. Furthermore, preoperative patients with iron deficiency should 
be treated early with oral or intravenous iron, when appropriate, to avoid preventable intraoperative transfusion.

Although generally low, the risk of adverse events from transfusion, including alloimmunization, transfusion reactions, and infection are higher than the risks of adverse events from oral or intravenous iron replacement [36,37]. Transfusion is also more costly than iron replacement, particularly oral iron replacement which can cost as little as five cents a day $[33,38]$. Thus in most cases it is both safer and more cost-effective to correct iron deficiency, rather than to transfuse red blood cells. Despite this, observational data suggests that iron replacement is under-utilized in adult and pediatric settings, and that transfusion continues to be used unnecessarily as a first-line strategy for severe, but stable iron deficiency anemia [39-41].

The fifth CW item highly relevant and important to the practice of hematology is from ASCO. ASCO recommends that clinicians avoid using positron emission tomography (PET) or PET-CT scanning to routinely monitor for cancer recurrence in patients who have finished cancer treatment and are asymptomatic. PET is an enormously powerful diagnostic and staging tool in a wide variety of cancers. However, there is little evidence that routine surveillance with PET scans can improve clinical outcomes in malignant hematology. In fact the limited observational data that is available suggests no survival advantage with the use of routine surveillance PET scans in patients with aggressive lymphoma [42,43]. Moreover, PET scanning is very expensive and is associated with a significant dose of radiation which is additive to radiation doses from CT. It has been estimated that depending on the scanning protocol used, a single PET-CT scan in a 20 -year old woman is associated with a $0.2-0.5 \%$ increased lifetime attributable risk of cancer [44]. Lymphoma is the most common cancer among adolescents and young adults [45], thus it is important that malignant hematologists are cognizant of the risks of surveillance scans in young patients. In older patients, the attributable risk of cancer from scans is lower; however, there is also a risk of false positive results, requiring additional tests with incumbent hazards and costs. For all of these reasons, outside of a clinical trial, routine PET surveillance is not recommended in the management of patients with blood cancers.

The sixth item on ASH's list of highly relevant and important CW recommendations is an item from the American Academy of Hospice and Palliative Medicine (AAHPM). The AAHPM recommends against delaying palliative care for patients because they are pursuing disease-directed treatment. Over the past decade palliative care has transformed from a discipline concerned principally with alleviating suffering in the final months of life, to a branch of medicine offering guidance on improving quality of life for patients with serious illnesses and expertise in end of life care [46]. This transformation is extremely relevant to the care of patients with blood cancers.

A large body of literature suggests that patients with hematologic malignancy are less likely to be referred to palliative care services than patients with other cancers [47]. Patients with blood cancers are also more likely to experience intensive end of life care [48]. These findings are complex and likely in part reflect unique features of hematologic cancers and historical barriers to accessing palliative services for patients desiring transfusion or other forms of active treatment $[49,50]$. Nonetheless, there is compelling evidence that early involvement of palliative care services improves quality of life, patient satisfaction, care giver satisfaction and in some settings can improve overall survival [51-53]. Incorporating palliative care into cancer care, particularly early in the patient journey may also offer the possibility of substantial cost-savings [51,54]. Thus, increasing access to palliative care for patients with blood cancers, including those pursuing disease-directed treatment, may offer huge opportunities to improve care while also reducing health care costs.
The seventh item highlighted by the ASH CW Task Force is a recommendation from the Society of General Internal Medicine that advises clinicians not to place, or leave in place, peripherally inserted central catheters for patient or provider convenience. Central lines are frequently indicated in patients with blood diseases to facilitate the administration of chemotherapy, other infusions, and/or blood products in patients who have difficult intravenous access, require vesicants, and/or need very frequent infusions. However, one-third of central venous catheters are placed for "weaker" indications such as facilitating blood draws or in case of clinical deterioration [55]. Further, more than $15 \%$ of these patients will have a catheter related complication [56]. Unfortunately, many patients for whom central lines are helpful such as patients with cancer or sickle cell disease, are also patients at especially high risk of line-related complications. Central access lines are a leading cause of iatrogenic infection [57,58] and are associated with increased ICU stay and mortality [59]. Central lines also carry an important risk of thrombosis [60] which can lead to catheter malfunction and requires limited duration anticoagulation, regardless of whether the catheter is removed. This commitment to anticoagulation predisposes patients to anticoagulation-related bleeding complications and costs. As a result of these common complications, providers, and patients should weigh the risks and benefits of central venous access before pursuing or continuing a line. The first step in this conscious effort to reduce iatrogenic complications is to improve the provider's awareness of the indwelling catheter. A recent study showed that $21 \%$ of physicians were unaware that their patient had a central venous catheter limiting their ability to make informed decisions about catheter retention [55]. Repeated daily reassessment of the need for an indwelling catheter is vital to prevent patient harm and reduce health care costs.

The eighth CW item of high relevance and importance to the care of patients with blood diseases is another recommendation from ASCO. ASCO recommends against the use of white cell stimulating factors (WCSFs) for the primary prevention of neutropenia in patients receiving nondose-dense chemotherapy with less than a $20 \%$ risk of neutropenia. Many patients with indolent lymphoma fit in this low risk category. In some patient populations WCSFs are associated with a decreased risk of hospitalization and possibly with a decreased risk of infection. However, improvements in survival have not been demonstrated in any populations [60]. WCSFs are expensive and even in patients with a greater than $20 \%$ risk of neutropenia, such as patients with diffuse large B cell lymphoma, the use of WCSFs has an unfavorable cost-effectiveness profile [61]. As well, this therapy can cause moderate to severe bone pain. Finally, some patients have to bear the cost of WCSFs themselves, contributing to the financial burden of their cancer therapy. Thus, hematologists are advised to consider the relative risks, benefits, and cost of WCSFs before prescribing them.

The ninth item on our list of high priority $\mathrm{CW}$ items is a recommendation from the American College of Preventive Medicine which advises clinicians to not use expensive medications when an equally effective and lower-cost medication is available. This recommendation is especially important to hematologists given the rapid pace of change in our field and the introduction of many life-saving, but high cost medications. Targeted oral chemotherapy drugs and new oral anticoagulants are examples where multiple treatment options exists, some of which are associated with very high costs. Health care expenses are the leading cause of bankruptcy in the United States and patients with cancer appear to be especially at risk $[62,63]$. The financial burden of care can lead to nonadherence with treatments [64], depleted savings, and even to patients cutting back on other necessities such as food and clothing [65]. Evidence suggests that patients welcome provider input on ways to decrease their health care costs 
[66], and offering lower cost, equally effective medicines to our patients is one way that providers can help.

From a societal perspective, drug expenses are an important factor in the rising cost of cancer care [67]. A recent survey revealed strong support from key stakeholders in oncology care on the importance of Medicare developing cost-control measures to limit reimbursement for drugs where less expensive but equally effective alternatives are available [68]. Recommending lower cost options that are equally efficacious has three potential benefits: first it can directly contribute to decreasing a patient's financial burden, second it can decrease payer costs freeing up resources for other needs, and third it may indirectly influence competing products to lower their prices.

The final recommendation highlighted by the ASH CW Task Force is a suggestion from the American Association for the Study of Liver Diseases (AASLD). The AASLD recommends that physicians not routinely transfuse fresh frozen plasma and/or platelets prior to abdominal paracentesis or endoscopic variceal band ligation. This recommendation is relevant to hematologists as hematologists may be called upon to provide advice regarding the need for transfusion in the above settings. As well, hematologists are often consulted when hospitals develop policies around periprocedural transfusion.

Our current knowledge of end-stage liver disease indicates that bleeding in this patient population is a function of not only deranged hemostasis but perhaps more importantly of hemodynamic alterations due to portal hypertension, endothelial dysfunction, bacterial infections, and renal failure. Patients with cirrhosis frequently experience thrombocytopenia due to portal hypertension, splenomegaly, and decreased thrombopoietin production; however, in this setting thrombocytopenia is usually mild and most patients can undergo low risk invasive procedures without platelet transfusion [69]. In fact, a platelet count of $60 \times 10^{9} / \mathrm{L}$ in cirrhotic patients is usually sufficient to preserve thrombin generation comparable to a healthy subject [70].

Similarly, patients with liver disease often have a prolonged prothrombin time (PT) and an increased international normalized ratio (INR); however, PT/INR is a poor measure of bleeding risk in this setting. In liver disease, primary hemostasis, coagulation, and fibrinolysis are disrupted in a manner which impacts both endogenous proand anticoagulants [71], routine hemostasis tests fail to predict bleeding tendency in liver disease. Contrary to popular belief, patients with chronic liver disease are not naturally "autoanticoagulated". Patients with cirrhosis are generally not protected from and may even be at increased risk for thrombosis, particularly in the splanchnic vessel bed. Furthermore, the ability of plasma or platelet transfusions to pre- vent or stop bleeding in patients with cirrhosis is unproven. Thus, the use of blood products to "correct" a perceived bleeding propensity may expose patients to a risk of adverse events with little expectation of benefit.

In addition, unnecessary transfusion is expensive and may contribute to blood product shortages. Platelet concentrates in particular have a relatively short shelf-life and the blood system is especially vulnerable to platelet shortages. Clinicians are advised to use past and current bleeding events to assess bleeding risk and to avoid the routine use of blood products prior to low risk procedures in patients with liver disease.

The ASH CW task force developed a method to identify CW recommendations from other societies that are both relevant and important to the practice of hematology and used this method to develop a top ten list of non-ASH Choosing Wisely recommendations. The recommendations highlighted through this process come from a broad range of parent societies, underlining the collaborative and crosscutting nature of medical practice. It is likely that other branches of medicine may similarly find relevance and utility in CW recommendations from outside their own field. The method we have developed could be easily adapted to identify recommendations relevant and important to other medical fields and thereby further extend the lessons and impact of the ABIM Choosing Wisely campaign.

\section{Acknowledgments}

This work was supported by the American Society of Hematology. Robert Plovnick and Patrick Irelan (ASH Staff) provided administrative and organizational assistance to the project. Dr's. Shannon Bates, Marc Rodger and Jeannie Callum provided advice and/or references for parts of the manuscript.

\section{Authorship Contributions}

Contributions: Members of the ASH 2015 Choosing Wisely Task Force: L. K. Hicks (Chair), H. Bering, K. R. Carson, J. Kleinerman, V. Kukreti, A. Ma, B. U. Mueller, S. H. O’Brien, J. A. Panepinto, M. C. Pasquini, A. Rajasekhar, R. Sarode, and W. A. Wood. All members of the task force contributed to study design and implementation. LK Hicks wrote the first draft of the manuscript. A. Rajasekhar contributed major revisions. All authors contributed to review and revisions of the manuscript.

\section{References}

1. Wolfson D, Santa J, Slass L. Engaging physicians and consumers in conversations about treatment overuse and waste: A short history of the choosing wisely campaign. Acad Med 2014;89:990995.

2. Rosenberg A, Agiro A, Gottlieb M, et al. Early trends among seven recommendations from the Choosing Wisely Campaign. JAMA Intern Med 2015;1-9. doi: 10.1001/jamainternmed.2015.5441.

3. http://www.choosingwisely.org/Accessed April 2, 2015.

4. http://www.choosingwisely.org/resources/updatesfrom-the-field/network-discovers-how-well-itsproviders-know-choosing-wisely/. Accessed Dec 21, 2015.

5. Hicks LK, Bering H, Carson KR, et al. The ASH Choosing Wisely ${ }^{\circledR}$ campaign: Five hematologic tests and treatments to question. Blood 2013; 122:3879-3883.

6. Hicks LK, Bering $H$, Carson $K R$, et al. Five hematologic tests and treatments to question. Blood 2014;124:3524-3528.

7. Haynes RB, Cotoi C, Holland J, et al. Secondorder peer review of the medical literature for clinical practitioners. JAMA 2006;295:18011808.

8. Jones J, Hunter D. Consensus methods for medical and health services research. BMJ 1995;311: 376-380.

9. Fleiss JL, Levin B, Paik MC. Statistical Methods for Rates and Proportions, 3rd ed. New York: Wiley; 2003.

10. Landis JR, Koch GG. The measurement of observer agreement for categorical data. Biometrics 1977;33:159-174.

11. Feng LB, Pines JM, Yusuf HR, Grosse SDUS. Trends in computed tomography use and diagnoses in emergency department visits by patients with symptoms suggestive of pulmonary embolism, 2001-2009. Acad Emerg Med 2013; 20:1033-1040.

12. Brenner DJ, Hall EJ. Computed tomography: an increasing source of radiation exposure. N Engl J Med 2007;357:2277-2284.

13. Hunsaker AR, Lu MT, Goldhaber SZ, Rybicki FJ. Imaging in acute pulmonary embolism with special clinical scenarios. Circ Cardiovasc Imaging 2010;3:491-500.

14. Parker MS, Hui FK, Camacho MA, Chung JK, Broga DW, Sethi NN. Female breast radiation exposure during CT pulmonary angiography. Am J Roentgenol 2005;185:1228-1233.

15. Morin DM, Lonstein JE, Stovall M, Hacker DG, Luckyanov N, Land CE. Breast cancer morality after diagnostic radiography: findings from the U.S. scoliosis cohort study. Spine 2000;25:20522063.

16. Carrier M, Righini M, Wells PS, et al. Subsegmental pulmonary embolism diagnosed by computed tomography: Incidence and clinical implications. A systematic review and metaanalysis of the management outcome studies. J Thromb Haemost 2010;8:1716-1722.

17. van Belle A, Büller HR, Huisman MV, et al. Effectiveness of managing suspected pulmonary embolism using an algorithm combining clinical probability, D-dimer testing, and computed tomography. JAMA 2006;295:172.

18. Singh B, Mommer SK, Erwin PJ, Mascarenhas SS, Parsaik AK. Pulmonary embolism rule-out criteria (PERC) in pulmonary embolism-Revisited: A systematic review and meta-analysis. Emerg Med J 2013;30:701-706.

19. Kline JA, Jones AE, Shapiro NI, Hernandez J, Hogg MM, Troyer J, Nelson RD. Multicenter, randomized trial of quantitative pretest probability to reduce unnecessary medical radiation 
exposure in emergency department patients with chest pain and dyspnea. Circ Cardiovasc Imaging 2014;7:66-73.

20. Chandra A, Copen CE, Stephen EH. Infertility and impaired fecundity in the United States, 1982-2010: Data from the National Survey of Family Growth. Natl Health Stat Rep 2013; 67:1-67.

21. Thomas ME, McLain AC, Louis JF, King RB, Trumble AC, Sundaram R, Buck Louis GM. Prevalence of infertility in the United States as estimated by the current duration approach and a traditional constructed approach. Fertil Steril 2013;99:1324

22. Kuperman A, Di Micco P, Brenner B. Women's Health 2011;7:545-553.

23. Casadei L, Puca F, Privitera L, Zamaro V, Emidi E. Inherited thrombophilia in infertile women: Implication in unexplained infertility. Fertil Steril 2010;94:755-757.

24. Levi M. Twenty-five million liters of blood into the sewer. J Thromb Haemost 2014;12:1592.

25. Melanson SE, Szymanski T, Rogers SO, et al. Utilization of arterial blood gas measurements in a large tertiary care hospital. Am J Clin Pathol 2007;127:604-609.

26. Stilwelll JA, Young D, Cunnington A. Evaluation of laboratory tests in hospitals. Ann Clin Biochem 1980;17:281.

27. Hindmarsh JT, Lyon AW. Strategies to promote rational clinical chemistry test utilization. Clin Biochem 1996;29:291-299.

28. Boland BJ, Wollan PC, Silverstein MD. Yield of laboratory tests for case-finding in the ambulatory general medical examination. Am J Med 1996;101:142-152.

29. Peixoto AA Jr, Meneses FA, Barbosa BP, et al. Laboratory routine in the ICU: A practice to be abolished? Crit Care 2013;17:P12.

30. Chant C, Wilson G, Friedrich JO. Anemia, transfusion, and phlebotomy practices in critically ill patients with prolonged ICU length of stay: A cohort study. Crit Care 2006;10:R140.

31. Goddard K, Austin SJ. Appropriate regulation of routine laboratory testing can reduce the costs of associated with patient stay in the intensive care unit. Crit Care 2011;15:P133.

32. Tawfik B, Collins JB, Fino NF, Miller DP, Jr. House Officer-Driven Reduction in Laboratory Utilization. South Med J 2016;109:5-10.

33. Pusic MV, Dawyduk BJ, Mitchell D. Opportunistic screening for iron-deficiency in 6-36 month old children presenting to the paediatric emergency department. BMC Pediatr 2005;5:42.

34. Nelson AL, Ritchie JJ. Severe anemia from heavy menstrual bleeding requires heightened attention. Am J Obstet Gynecol 2015;213:97.e1-e6.

35. Knight T, D'Sylvia L, Moore B, et al. Burden of iron deficiency anemia in a bariatric surgery population in the United States. J Manag Care Spec Pharm 2015;21:946-954.

36. Bolton-Maggs PH, Cohen H. Serious hazards of transfusion (SHOT) haemovigilance and progress is improving transfusion safety. $\mathrm{Br} \mathrm{J} \mathrm{Hae}-$ matol 2013;163:303.

37. Chertow GM, Mason PD, Vaage-Nilsen $\mathrm{O}$, Ahlmén J. Update on adverse drug events associated with parenteral iron. Nephrol Dial Transplant 2006;21:378.

38. Callum JL, Waters JH, Shaz BH, Sloan SR, Murphy MF. The AABB recommendations for the Choosing Wisely campaign of the American Board of Internal Medicine. Transfusion 2014, 54:2344-2352

39. Rohrig G, Klossok W, Becker I, et al. Prevalence of anemia among elderly patients in an emergency room setting. Eur Geriatr Med 2014;5:3-7.

40. Saxena S, Rabinowitz AP, Johnson C, et al. Iron-deficiency anemia: A medically treatable chronic anemia as a model for transfusion overuse. Am J Med 1993;94:120-124.

41. Grey DE, Finlayson J. Red cell transfusion for iron deficiency anaemia: A retrospective audit at a tertiary hospital. Vox Sang 2008;94:138-142.

42. Hiniker SM, et al. Value of surveillance studies for patients with stage I to II diffuse large B-cell lymphoma in the rituximab era. Int J Radiat Oncol Biol Phys 2015;92:99-106.

43. Cheah CY, et al. Limited clinical benefit for surveillance PET-CT scanning in patients with histologically transformed lymphoma in complete metabolic remission following primary therapy. Ann Hematol 2014;93:1193-1200.

44. Huang B, Law MW, Khong P. Whole-body PET/CT scanning: Estimation of radiation dose and cancer risk. Radiology 2009;251:166-174.

45. Bleyer A, O'Leary M, Barr R, Ries LAG, editors. Cancer Epidemiology in Older Adolescents and Young Adults 15 to 29 Years of Age, Including SEER Incidence and Survival: 1975-2000. Bethesda, MD: National Cancer Institute, NIH Pub. No. 06-5767; 2006.

46. Kelley AS, Morrison RS. Palliative care for the seriously Ill. N Engl J Med 2015;373:747-755.

47. Howell DA, Shellens R, Roman E, et al. Haematological malignancy: Are patients appropriately referred for specialist palliative and hospice care? A systematic review and meta-analysis of published data. Palliat Med 2011;25:630-641.

48. Hui D, Didwaniya N, Vidal M, et al. Quality of end-of-life care in patients with hematologic malignancies: A retrospective cohort study. Cancer 2014;120:1572-1578

49. LeBlanc TW. Palliative care and hematologic malignancies: Old dog, new tricks? JOP 2014;10: e404-e406.

50. Odejide OO, Salas Coronado DY, Watts CD et al. End-of-life care for blood cancers: A series of focus groups with hematologic oncologists. J Oncol Pract 2014;10:e396-e403.

51. Smith TJ, Temin S, Alesi ER, et al. American Society of Clinical Oncology Provisional Clinical Opinion: The Integration of Palliative Care Into Standard Oncology Care. J Clin Oncol 2012;30: 880-887.

52. Temel JS, Greer JA, Muzikansky A, et al. Early palliative care for patients with metastatic nonsmall-cell lung cancer. N Engl J Med 2010;363: 733-742.

53. Bakitas MA, Tosteson TD, Li Z, et al. Early versus delayed initiation of concurrent palliative oncology care: Patient outcomes in the ENABLE III Randomized Controlled Trial. J Clin Oncol 2015;33:1438-1445

54. May P, Garrido MM, Cassel JB, et al. Prospective cohort study of hospital palliative care teams for inpatients with advanced cancer: Earlier consultation is associated with larger costsaving effect. J Clin Oncol 2015;33:2745-2752.

55. McDonald EC, Lee TC. Reduction of central venous catheter use in medical inpatients through regular physician audits using an online tool. JAMA Intern Med 2015;175:1232.

56. McGee DC, Gould MK. Preventing complications of central venous catheterization. N Engl J Med 2003;348:1123-1133.

57. Raad I, Hanna H, Maki D. Intravascular catheter-related infections: Advances in diagnosis, prevention, and management. Lancet Infect Dis 2007;7:645-657.

58. Schiffer CA, Mangu PB, Wade JC, et al. Central venous catheter care for the patient with cancer: American Society of Clinical Oncology clinical practice guideline. J Clin Oncol 2013;31:13571370.

59. Gahlot R, Nigam C, Kumar V, Yadav G, Anupurba S. Catheter-related bloodstream infections. Int J Crit Illn Inj Sci 2014;4:162-167.

60. Smith TJ, Bohlke K, Lyman GH, et al. Recommendations for the use of WBC growth factors: American Society of Clinical Oncology Clinical Practice Guideline Update. J Clin Oncol 2015; 33:3199-3212.

61. Chan KK, Siu E, Krahn MD, Imrie K, Alibhai SM. Cost-utility analysis of primary prophylaxis versus secondary prophylaxis with granulocyte colony-stimulating factor in elderly patients with diffuse aggressive lymphoma receiving curative-intent chemotherapy. J Clin Oncol 2012;30:1064-1071.

62. Himmelstein DU, Thorne D, Warren E, Woolhandler S. Medical bankruptcy in the United States, 2007: Results of a national study. Am J Med 2009;122:741-746.

63. Ramsey S, Blough D, Kirchhoff A, et al. Washington State cancer patients found to be at greater risk for bankruptcy than people without a cancer diagnosis. Health Aff (Millwood) 2013; 32:1143-1152.

64. Dusetzina SB, Winn AN, Abel GA, et al. Cost sharing and adherence to tyrosine kinase inhibitors for patients with chronic myeloid leukemia. J Clin Oncol 2014;32:306-311.

65. Zafar SY, Peppercorn JM, Schrag D, et al. The financial toxicity of cancer treatment: A pilot study assessing out-of-pocket expenses and the insured cancer patient's experience. Oncologist 2013;18:381-390.

66. Zafar SY, Abernethy AP, Tulsky JA, et al. Financial distress, communication, and cancer treatment decision-making: Does cost matter? J Clin Oncol 2013;31:390 (abstr 6506).

67. Smith TJ, Hillner BE. Bending the cost curve in cancer care. N Engl J Med 2011;364:2060-2065.

68. Gogineni K, Shuman K, Chinn D, et al. Making cuts to medicare: The views of patients, physicians, and the public. J Clin Oncol 2015;33:846853.

69. Runyon BA. Management of adult patients with ascites due to cirrhosis. Hepatology 2004;39:841856

70. Tripodi A, Primignani $M$, Chantarangkul V, et al. Thrombin generation in patients with cirrhosis: The role of platelets. Hepatology 2006;44: 440-445.

71. Tripodi A, Mannucci PM. The coagulopathy of chronic liver disease. N Engl J Med 2011;365: 147-156. 